\title{
Perioperative cardiovascular monitoring of high-risk patients: a consensus of 12
}

\author{
Jean-Louis Vincent ${ }^{1 *}$, Paolo Pelosi ${ }^{2}$, Rupert Pearse ${ }^{3}$, Didier Payen ${ }^{4}$, Azriel Perel $^{5}$, Andreas Hoeft ${ }^{6}$, Stefano Romagnoli ${ }^{7}$, \\ V Marco Ranieri ${ }^{8}$, Carole Ichai ${ }^{9}$, Patrice Forget ${ }^{10}$, Giorgio Della Rocca ${ }^{11}$ and Andrew Rhodes ${ }^{12}$
}

\begin{abstract}
A significant number of surgical patients are at risk of intra- or post-operative complications or both, which are associated with increased lengths of stay, costs, and mortality. Reducing these risks is important for the individual patient but also for health-care planners and managers. Insufficient tissue perfusion and cellular oxygenation due to hypovolemia, heart dysfunction or both is one of the leading causes of perioperative complications. Adequate perioperative management guided by effective and timely hemodynamic monitoring can help reduce the risk of complications and thus potentially improve outcomes. In this review, we describe the various available hemodynamic monitoring systems and how they can best be used to guide cardiovascular and fluid management in the perioperative period in high-risk surgical patients.
\end{abstract}

\section{Introduction}

An estimated 230 million surgical procedures are performed each year around the world [1], and a significant number are in patients at risk of intra- or post-operative complications or both. Although less than $15 \%$ of inpatient procedures are performed in high-risk patients, such patients account for $80 \%$ of deaths [2-4]. Even for those patients who survive to leave hospital, postoperative complications remain an important determinant of functional recovery, long-term survival [5], and health-care costs. Thus, mitigation of these risks is important not only for the individual patient but also for health-care managers.

The risk of perioperative complications is related to various factors, including patient status and comorbidities,

\footnotetext{
* Correspondence: jvincen@ulb.ac.be

'Department of Intensive Care, Erasme Hospital, Université Libre de Bruxelles, 808 route de Lennik, 1070 Brussels, Belgium

Full list of author information is available at the end of the article
}

the type of surgery performed and its duration, the degree of urgency, the skills and experience of the operating and anesthetic teams, and the post-operative management. Insufficient tissue perfusion and cellular oxygenation due to hypovolemia, heart dysfunction or both is one of the leading causes of perioperative complications and poor outcomes [6-9]. Thus, effective fluid management to prevent and treat hypo/hypervolemia and titration of vasoactive drugs for heart dysfunction are crucial to maintain adequate oxygen delivery $\left(\mathrm{DO}_{2}\right)$ and prevent fluid overload and its consequences [10-12]. Therefore, selecting the most appropriate hemodynamic monitoring device (for diagnosis and to guide therapies) may be an important first step in reducing the risk of complications. The aims of this review are to describe the available hemodynamic monitoring systems and to evaluate the most appropriate clinical setting for each.

\section{Basic hemodynamic monitoring}

Clinical examination remains an important initial step in the hemodynamic assessment of high-risk surgical patients. However, individual vital signs often lack the specificity and sensitivity that are needed to guide hemodynamic management. For example, blood pressure is a variable influenced by both cardiac output $(\mathrm{CO})$ and vascular tone; hence, blood pressure can remain within the normal range in the presence of low-flow states, including hypovolemia, as a result of increased peripheral vascular resistance. Similarly, heart rate may fail to reflect the development of hypovolemia under anesthesia [13].

Combining and integrating parameters from various hemodynamic monitoring systems may help improve our understanding of hemodynamic status [14]. For example, the combination of arterial pressure and the partial pressure of end-tidal carbon dioxide $\left(\mathrm{PetCO}_{2}\right)$ can help differentiate between vasodilation and low $\mathrm{CO}$ as a cause of hypotension $\left(\mathrm{PetCO}_{2}\right.$ transiently decreases when $\mathrm{CO}$ decreases) and may prevent 'reflex' fluid administration 
whenever blood pressure decreases. Similarly, a reduction in the $\mathrm{PetCO}_{2}$ value for the same minute ventilation (in the absence of hypothermia) suggests decreased pulmonary blood flow (and thus $\mathrm{CO}$ ) and may serve as a trigger for more advanced hemodynamic monitoring.

\section{Arterial pressure}

Continuous invasive measurement of arterial pressure helps identify the rapid fluctuations in arterial pressure that may occur in high-risk patients. Artifacts (over- or under-damping) should be carefully identified and eliminated, especially when systolic-diastolic components and waveform have to be analyzed. Non-invasive techniques for continuous measurement of blood pressure are usually performed in peripheral arteries and may become unreliable in case of vasoconstriction or low peripheral flow. Non-invasive assessment of pressure waveforms from more central measurement sites, such as the brachial artery, may be a valuable option in the future.

\section{Central venous pressure}

A central venous catheter (CVC) is often used for administration of fluids, vasopressors, and inotropes and for measurement of central venous pressure (CVP). Since transmural CVP is the only value related to right ventricular (RV) preload but is not commonly monitored, interpretation of CVP values must take into account intrathoracic pressure changes, which are largely influenced by mechanical ventilation. Thus, changes in $\mathrm{CVP}$ with concomitant $\mathrm{CO}$ variations give an indication of RV function and potential peripheral venous congestion, the latter of which is an important factor for organ perfusion [15]. In addition, careful checking of the CVP wave may help to diagnose tricuspid regurgitation with a ' $\mathrm{v}$ ' wave during systole. When the CVP is low $(<6 \mathrm{~mm}$ $\mathrm{Hg}$ ) with a concomitant low $\mathrm{CO}$, there is almost certainly some degree of hypovolemia. Although changes in CVP correlate poorly with changes in CO [16] (as for pulmonary artery occlusion pressure), they can be used to assess the dynamic response to a fluid challenge [17] and to diagnose severe hypovolemia or cardiac dysfunction or both, especially where other monitoring systems are not available.

\section{Cardiac output monitoring}

The perioperative period is characterized by large variations in whole body oxygen consumption $\left(\mathrm{VO}_{2}\right)$. The main goal in this period is to maintain an adequate $\mathrm{DO}_{2}$ to meet the fluctuating tissue oxygen requirements. Global $\mathrm{DO}_{2}$ is determined by $\mathrm{CO}$ and the oxygen content of arterial blood, and so after correction of hypoxemia and anemia (topics that will not be dealt with here), maintenance of an adequate $\mathrm{CO}$ is the next logical step to improve $\mathrm{DO}_{2}$. There are various methods available for monitoring $\mathrm{CO}$ [18], although a survey indicated that $\mathrm{CO}$ is routinely monitored in high-risk surgical patients by only about $35 \%$ of practitioners in Europe and North America [19] (Table 1).

\section{Doppler echocardiography}

Though difficult to use as a continuous monitor of $\mathrm{CO}$ with conventional probes, transthoracic (TTE) or transesophageal (TEE) echocardiography can provide immediate point-of-care assessment of acute hemodynamic changes in selected patients. Echo techniques can also help to visualize the lungs, but this is beyond the scope of this review. Obviously, it is not possible to use TEE in all types of surgery. In addition to the estimation of $\mathrm{CO}$ (usually easier with TEE than with TTE), Doppler echocardiographic examination can provide an indication of cardiac function because it allows visualization of the cardiac chambers, valves, and pericardium [20]. It also allows measurement of the ejected stroke volume (SV) and derived left ventricular (LV) function parameters.

TEE provides several views, including the following:

- The LV short-axis view, which can be used to evaluate LV function. Calculation of the LV fractional area contraction, or the simpler 'eyeballing method',

\begin{tabular}{|c|c|c|}
\hline & $\begin{array}{l}\text { ASA } \\
\text { respondents } \\
(n=237)\end{array}$ & $\begin{array}{l}\text { ESA } \\
\text { respondents } \\
(n=195)\end{array}$ \\
\hline Answer options & $\begin{array}{l}\text { Response } \\
\text { percentage }\end{array}$ & $\begin{array}{l}\text { Response } \\
\text { percentage }\end{array}$ \\
\hline Invasive arterial pressure & $95.4 \%$ & $89.7 \%$ \\
\hline Central venous pressure & $72.6 \%$ & $83.6 \%$ \\
\hline Non-invasive arterial pressure & $51.9 \%$ & $53.8 \%$ \\
\hline Cardiac output & $35.4 \%$ & $34.9 \%$ \\
\hline Pulmonary capillary wedge pressure & $30.8 \%$ & $14.4 \%$ \\
\hline Transesophageal echocardiography & $28.3 \%$ & $19.0 \%$ \\
\hline Systolic pressure variation & $20.3 \%$ & $23.6 \%$ \\
\hline Plethysmographic waveform variation & $17.3 \%$ & $17.9 \%$ \\
\hline Pulse pressure variation & $15.2 \%$ & $25.6 \%$ \\
\hline Mixed venous saturation $\left(\mathrm{ScvO}_{2}\right)$ & $14.3 \%$ & $15.9 \%$ \\
\hline Central venous saturation $\left(\mathrm{SvO}_{2}\right)$ & $12.7 \%$ & $33.3 \%$ \\
\hline Oxygen delivery $\left(\mathrm{DO}_{2}\right)$ & $6.3 \%$ & $14.4 \%$ \\
\hline Stroke volume variation & $6.3 \%$ & $21.5 \%$ \\
\hline Near-infrared spectroscopy & $4.6 \%$ & $5.1 \%$ \\
\hline Global end-diastolic volume & $2.1 \%$ & $8.2 \%$ \\
\hline
\end{tabular}

From [19]. ASA, American Society of Anesthesiology; ESA, European Society of Anaesthesiology. 
informs about the kinetic (contractile) state and the shape (volume) of the heart. Poor contractility may indicate that inotropic support could help, and 'kissing' of the papillary muscle may indicate the need for fluids if the right heart is functioning normally. The short-axis view may also be used to identify septal dyskinesia. The finding of an RV D-shape may suggest the presence of RV dysfunction/failure, indicating a non-adaptation to an acute increase in RV afterload (pulmonary embolism) or RV myocardial ischemia.

- The four-chamber view, which can help in assessing LV and RV function by evaluation of the right-to-left size ratio (normal $<0.6$ ).

In more advanced echocardiographic evaluation, fluid status and fluid responsiveness can also be assessed in mechanically ventilated patients by means of the superior vena cava collapsibility index (TEE bicaval view) or inferior vena cava distensibility index (TTE subcostal view). In addition, echocardiography allows the rapid and reliable estimation of SV. Finally, there are particular and specific conditions in which diagnosis and treatment are strictly related to the echocardiographic examination (for example, pericardial effusion, valve disruptions, aortic dissection, and systolic anterior motion of the mitral valve).

A miniaturized, disposable monoplane TEE probe that can be left in place for up to 72 hours $\left(\right.$ ClariTEE $^{\mathrm{mm}}$, ImaCor Inc., Garden City, NY, USA) was recently introduced and has the potential to provide ongoing qualitative cardiac assessment [21]. We believe that, where expert echocardiography skills are not available, training programs should be developed to ensure that clinicians taking care of the high-risk patient are familiar with at least the basic applications of TTE and TEE.

\section{Pulmonary artery catheter}

Though criticized in recent years for its intrinsic invasiveness and no clear evidence of improved outcomes [22-25], the pulmonary artery catheter (PAC) is the only tool that provides continuous monitoring of pulmonary artery pressure, right-sided and left-sided filling pressures, $\mathrm{CO}$, and mixed venous oxygen saturation $\left(\mathrm{SvO}_{2}\right)$. Although the PAC can now be largely replaced by less invasive hemodynamic monitoring techniques in many cases, in some complex clinical situations (for example, cardiac surgery, organ transplant surgery, and surgery associated with major fluid shifts or high risk of respiratory failure or in patients with compromised RV function), the PAC still represents a valuable tool when used by physicians adequately trained to correctly interpret and apply the data provided [26,27]. In such patients, the PAC can be inserted for limited periods of time and removed when no longer necessary.

\section{Other cardiac output monitoring devices Pulse contour analysis}

SV can be estimated continuously by analysis of the arterial pressure waveform, usually derived from an indwelling arterial catheter or by a non-invasive finger pressure cuff. To calculate SV from a pressure trace, the algorithms used by these devices have to compensate for the overall impedance of the system on the basis of the estimation of compliance and resistance of the cardiovascular tree. In this regard, optimization of the input signal is imperative, and severe distortions of the arterial waveform (for example, severe arrhythmias and multiple ectopic beats) and inadequate response of fluid-filled transducer systems (that is, over- and under-damping) [28] can result in unreliable $\mathrm{CO}$ measurement.

\section{Calibrated devices}

- The PiCCOplus ${ }^{\text {tim }} / \mathrm{PiCCO}_{2}{ }^{\text {Tw }}$ system (Pulsion Medical Systems, Munich, Germany) consists of a thermistor-tipped catheter which is usually placed in the femoral artery, although catheters for radial, axillary, or brachial applications are also available. The PiCCO ${ }^{\text {ra }}$ device measures $\mathrm{CO}$ by transpulmonary thermodilution, which additionally provides the computation of volumetric preload parameters-global end-diastolic volume (GEDV) and intrathoracic blood volume-and extravascular lung water (EVLW). The $\mathrm{CO}$ measured by the Stewart-Hamilton principle from the thermodilution curve is used to calibrate a pulse contour algorithm, which measures the area under the systolic pulse pressure curve and calculates the SV in order to provide beat-by-beat $\mathrm{CO}$ measurement. The system has to be frequently recalibrated, at least every 8 hours in hemodynamically stable patients and more often if changes in vasoactive support are provided [29]. The system has been validated in a variety of clinical settings [30].

- The EV1000 ${ }^{\mathrm{m}} / \mathrm{Volum}$ View $^{\mathrm{Tw}}$ system (Edwards Lifesciences, Irvine, CA, USA) has been more recently introduced and is analogous to the $\mathrm{PiCCO}^{\text {ix }}$ monitor, using pulse wave analysis to calculate $\mathrm{CO}$. A proprietary thermistor-tipped femoral artery catheter and a separate sensor are the main components of the system. This system requires calibration by transpulmonary thermodilution. It has been validated against the $\mathrm{PiCCO}^{\mathrm{m}}$ and transpulmonary thermodilution in critically ill patients [31].

- The LiDCO ${ }^{\mathrm{Tm}}$ plus system (LiDCO Ltd, Cambridge, UK) uses pulse power analysis to calculate SV and therefore is not technically a pulse contour device. The algorithm is based on the principle of conservation of mass (power), assuming a linear relationship between the net power change and the net flow in the vascular system. This system requires 
correction for vascular compliance, with calibration using a transpulmonary lithium indicator dilution technique performed via an indwelling arterial catheter. It has been validated in critically ill patients $[32,33]$.

\section{Uncalibrated devices (without external calibration) With preloaded data}

- The PulsioFlex ${ }^{\mathrm{Tm}}$ system (Pulsion Medical Systems) displays trends of estimated $\mathrm{CO}$ by using the patient's anthropometric and demographic characteristics (necessary for internal calibration), analysis of the arterial pressure tracing, and a proprietary algorithm for data analysis. The system requires a dedicated additional sensor, which can be connected to a regular arterial pressure catheter. Based on the same pulse contour algorithm used by the $\mathrm{PiCCO}^{\mathrm{rm}}$, the device can be calibrated by entering a $\mathrm{CO}$ obtained from an external source (for example, Doppler echocardiography) or by the system's own internal algorithm.

- The LiDCO ${ }^{\text {rit }}$ rapid (LiDCO Ltd) device uses the same algorithm as the $\mathrm{LiDCO}^{\mathrm{m}}$ plus system, but instead of lithium dilution, nomograms based on the patient's age, weight, and height are used to estimate SV and CO (so-called 'nominal' SV and CO). An externally estimated $\mathrm{CO}$ can be used to calibrate the device.

- The FloTrac ${ }^{\mathrm{Tt}} /$ Vigileo $^{\mathrm{Tw}}$ system (Edwards Lifesciences) consists of a proprietary transducer $\left(\right.$ FloTrac $^{\mathrm{Tm}}$ ) connected to a standard (radial or femoral) arterial catheter. Individual demographic variables (age, sex, height, and weight) and a database containing $\mathrm{CO}$ variables derived by using the PAC are used to calculate impedance and a 'normal' SV against which the standard deviation of the pulse pressure sampled during a 20-second interval is correlated to estimate CO. Arterial waveform analysis is used to calculate vascular resistance and compliance. The algorithm used by the Vigileo ${ }^{\text {tw }}$ device has been modified over time, and recent studies evaluating the device in the perioperative setting have shown an improved performance and a significant reduction in the time needed to adapt to vascular dynamics. In the intensive care unit (ICU) setting, concerns remain regarding the accuracy in situations of acute hemodynamic instability as well as hyperdynamic conditions, although recent software modifications seem to improve the reliability of $\mathrm{CO}$ measurements. The FloTrac ${ }^{\mathrm{Tm}} / \mathrm{VVigileo}^{\mathrm{Tm}}$ system has been shown to be suitable for integration into perioperative optimization protocols, resulting in improved clinical outcomes [34,35].
Without preloaded data

- The MostCare system (Vytech, Padua, Italy), powered by the pressure recording analytical method, performs a beat-to-beat estimation of $\mathrm{SV}$ and $\mathrm{CO}$ by analyzing the pressure waveform, sampled at high resolution $(1,000$ points per second $=1 \mathrm{kHz})$. The area under the pressure wave is determined during the whole cardiac cycle. In each phase, the method identifies specific points ('points of instability') characterized by modifications in velocity and acceleration in relationship to the previous and the subsequent point. All of these 'points of instability', mainly caused by reflected waves from the periphery (backward travelling waves), give the arterial pulse its specific profile, which is analyzed by MostCare for estimation of the vascular impedance $(\mathrm{Zt})$. The contribution of the reflected waves to the forward travelling wave can be accurately identified only with a very high sampling rate. The ability to update the $\mathrm{Zt}$ during each heart beat makes the system extremely reactive when abrupt changes in impedance occur (for example, changes in vascular tone) $[36,37]$. Although some promising clinical data are available [38], larger validation studies are needed to confirm these observations. A multicenter study comparing MostCare with echo-Doppler for CO measurement was recently completed (ClinicalTrials.gov identifier: NCT01678950).

\section{Non-invasive pulse contour analysis}

- Recently, several newly marketed monitors have purported to track changes in arterial pressure non-invasively from finger probes. These include the continuous non-invasive arterial pressure probe (used with the $\mathrm{LiDCO}^{\mathrm{m}}$ system) and the ClearSight device (Edwards Lifesciences). Based on the volumeclamp technique of Penaz [39] incorporated into a finger cuff, a brachial artery pressure waveform is reconstructed. The ClearSight monitor estimates $\mathrm{CO}$ on a beat-to-beat basis by dividing the integrated pulsatile systolic area by the aortic input impedance, which in turn is derived from a three-element Windkessel model incorporating patient-specific aortic mechanical characteristics [40]. Preliminary clinical validation studies, currently limited to a critical care setting and cardiac surgery, have shown acceptable agreements in $\mathrm{CO}$ when compared with thermodilution measurements performed with a PAC [41-44]. These monitors have the potential to track SV and $\mathrm{CO}$ in situations requiring early hemodynamic intervention when more invasive monitoring modalities are not readily available. 


\section{Doppler monitoring devices}

- Esophageal Doppler offers a minimally invasive determination of CO. The CardioQ ${ }^{\mathrm{mm}} / \mathrm{CardioQ}^{-} \mathrm{ODM}^{\mathrm{m}}$ (Deltex Medical Ltd, Chichester, UK) is the most commonly used device. Esophageal probes measure blood flow in the descending part of the aorta. SV is calculated by multiplying the cross-sectional area of the aorta (from nomograms based on height, weight, and age) by the blood flow velocity. Technical and methodological concerns regarding probe positioning and the use of nomograms have been raised.

- A transthoracic continuous Doppler CO monitor, the USCOM (Uscom, Sydney, Australia), is also available for intermittent SV and CO assessment. Using supra- or parasternal windows, flow velocity at the level of the aortic or pulmonary valves can be assessed non-invasively. Aortic diameter can be loaded from another measurement (two-dimensional echocardiography) or from a nomogram as mentioned above. The technique is rapid and can be used in adult and pediatric patients. Clinical validation studies have shown conflicting results, partially due to variations in signal acquisition inherent in the technique [45].

\section{Applied Fick principle and dye dilution}

- The NICO ${ }^{\mathrm{rm}}$ System (Novametrix Medical Systems, Wallingford, CT, USA), using the partial $\mathrm{CO}_{2}$ rebreathing method, applies the Fick principle to $\mathrm{CO}_{2}$ in patients who are intubated and mechanically ventilated via a disposable rebreathing circuit that is added to the ventilator tubing. $\mathrm{CO}_{2}$ production is calculated as the product of $\mathrm{CO}_{2}$ concentration and airflow during a breathing cycle, and arterial $\mathrm{CO}_{2}$ content is derived from end-tidal $\mathrm{CO}_{2}$ and its corresponding dissociation curve. The rebreathing loop can induce an intermittent partial rebreathing state in 3-minute intervals. This rebreathing cycle results in an increased end-tidal $\mathrm{CO}_{2}$, mimicking a decrease in $\mathrm{CO}_{2}$ production. The differences in these values can be used to calculate $\mathrm{CO}$. The system is not really clinically acceptable, because the assessment of $\mathrm{CO}$ is possible only in patients with fixed ventilator settings and good respiratory function with no relevant pulmonary shunt $[46,47]$.

- DDG-30 ${ }^{\circ}$ pulsed dye densitometry (Nihon Kohden, Tokyo, Japan) is based on the transpulmonary dye dilution technique using indocyanine green (ICG). Signal detection in the arterial blood is performed by transcutaneous optical absorbance measurements similar to pulse oximetry. $\mathrm{CO}$ is calculated from the ICG-dye dilution curve according to the Stewart-
Hamilton principle. Factors that compromise signal detection, such as vasoconstriction, interstitial edema, movement, or ambient light artifacts, all limit the reliability of CO assessment using this method [48].

\section{Bioimpedance and bioreactance}

- Electrical bioimpedance estimates CO continuously by detecting variations in thoracic or whole body impedance induced by cyclic changes in blood flow. Electrodes attached to the skin (BioZ, CardioDynamics, San Diego, CA, USA) or an endotracheal tube $\left(\mathrm{ECOM}^{\mathrm{T}}\right.$, Conmed Corporation, Utica, NY, USA) provide electric current stimulation, and signal variations are analyzed by using mathematical algorithms. The reliability of these systems is poor $[49,50]$.

- The Bioreactance ${ }^{\bullet}$ technique $\left(\mathrm{NICOM}^{\circledR}\right.$, Cheetah Medical Ltd, Maidenhead, Berkshire, UK) analyzes the variations in the frequency spectra associated with delivery of an oscillating electrical current. This technique may be somewhat superior to the bioimpedance technique $[51,52]$ but is dependent on body size [53] and the aeration of the lung. It is less accurate in diseased lungs in which reactance may be affected by the amount of EVLW and alveolar collapse or consolidation or both.

\section{Pitfalls in the interpretation of cardiac output}

Although $\mathrm{CO}$ can be measured with reasonable accuracy and precision with some of these systems, it is difficult to assess the optimal $\mathrm{CO}$ for an individual patient. A 'normal' or even high $\mathrm{CO}$ does not preclude the presence of inadequate regional and microcirculatory flow, and a low CO may be adequate in a context of low metabolic demand, especially during surgery under general anesthesia. Moreover, simple identification of a low $\mathrm{CO}$ does not tell us what to do about it. To correctly interpret the data acquired by any of the described devices, we need to combine/integrate several variables to help decide whether the $\mathrm{CO} / \mathrm{SV}$ is adequate and how it can be optimized in the most effective manner.

\section{How to select the best system}

All monitoring systems have unique characteristics in terms of accuracy, precision, validity, stability, and reliability [18]. Not all monitoring devices have been evaluated against the same set of criteria, and uncertainty remains regarding acceptance thresholds for the performance of $\mathrm{CO}$ monitors and the used reference techniques [54-57]. Clinicians must consider the technical limitations of each monitoring system and the potential trade-off between more invasive but highly accurate 
measurements of $\mathrm{CO}$ and less invasive but also less accurate modalities.

Several questions can be raised when considering choice of $\mathrm{CO}$ monitoring in the perioperative period:

1. Are we ready to accept a less accurate measurement in order to limit invasiveness? (Figure 1). A less accurate measurement may be acceptable if the trend analysis is reliable. Cost may also be an important issue.

2. Do we need continuous, semi-continuous, or intermittent measurements? Most complications after surgery do not have a sudden onset (except sudden cardiac failure due, for example, to myocardial infarction or pulmonary embolism) or an obvious cause (for example, massive bleeding during surgery) but develop slowly; therefore, semi-continuous or intermittent measurements may be acceptable. However, it should be noted that only beat-by-beat measurement of SV allows assessment of the response to preload-modifying maneuvers, such as a fluid challenge or passive leg raising (PLR) test.

3. Are calibrated or uncalibrated systems preferable? Non-calibrated systems are acceptable for the operating room (OR) or the post-anesthesia care unit (PACU) but may not be suitable for more complex cases, especially in the ICU. In unstable patients, there is a necessity to 're-calibrate' more often because of frequent changes in vascular tone and also because derived variables (for example, EVLW and GEDV) need to be re-calculated. A practical option may be to use an uncalibrated system in the OR/PACU and replace it with a calibrated system in the ICU.

4. What alarms do we need? A major problem for patient surveillance by telemetric monitoring is artifact robustness. Any system with too many false alarms is prone to failure as personnel become desensitized.

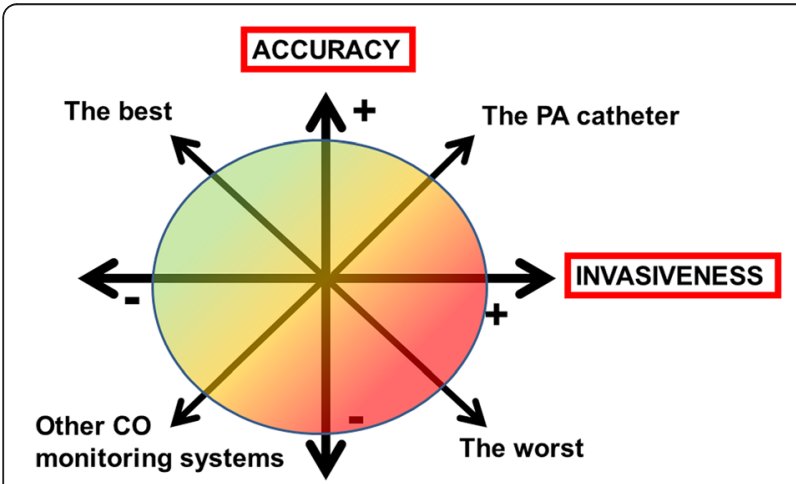

Figure 1 The compromise between accuracy and invasiveness of monitoring systems. CO, cardiac output; PA, pulmonary artery.
5. What kind of monitoring for what kind of patient? This is not a 'one size fits all' decision; rather, the optimal monitoring technique for each patient will vary depending on the degree of risk and the extent of the surgical procedure (Figure 2).

\section{Fluid management}

Inadequate fluid management may lead to reduced $\mathrm{CO}$ and $\mathrm{DO}_{2}$ to injured tissues, which is associated with an increased incidence of post-operative complications. Moreover, the systemic inflammatory response associated with tissue injury results in capillary leak and tissue edema. Fluid restriction and diuresis may decrease edema in patients with poor ventricular function but may also increase the incidence of acute kidney injury. Meanwhile, excessive fluid administration may lead to a range of adverse effects, including coagulopathy and edema of lungs, gut, and peripheral tissues (Figure 3). Retention of sodium and water following surgery may reduce fluid requirements. Once the patient is stabilized, fluids should be given only to correct deficit or continuing losses. Unfortunately, estimates of fluid deficit that are based on traditional physiological parameters, such as heart rate, blood pressure, and cardiac filling pressures, are not sufficient.

\section{Static indicators of preload}

- CVP: Many high-risk surgical patients have a CVC in place, and a CVC is a requirement for some devices needing calibration by thermodilution. Despite its limitations (vide supra), changes in CVP over time may be helpful to guide fluid

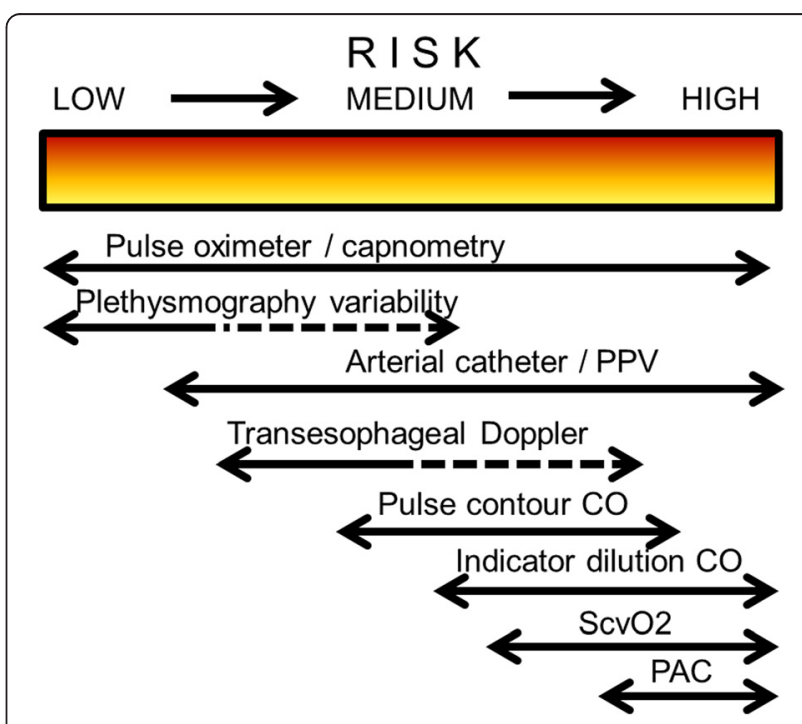

Figure 2 Possible choice of monitoring system in relation to a patient's degree of perioperative risk. CO, cardiac output; PAC, pulmonary artery catheter; PPV, pulse pressure variation; $\mathrm{SCVO}_{2}$, central venous oxygen saturation. 


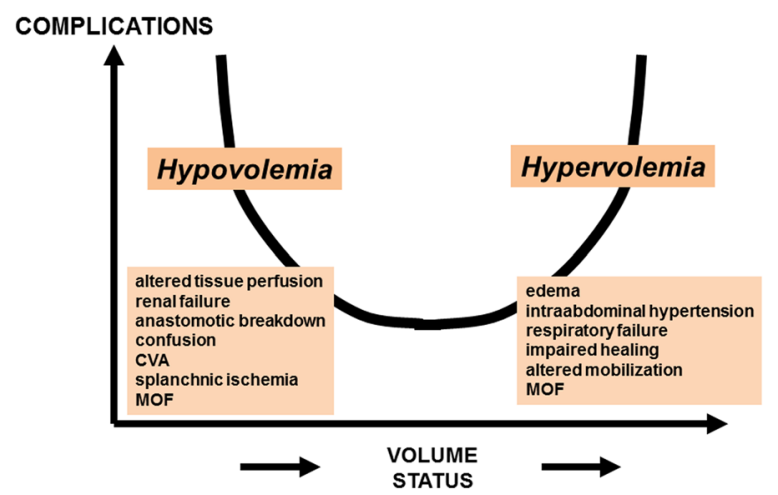

Figure $\mathbf{3}$ Both hypo- and hypervolemia are associated with more complications. CVA, cerebrovascular accident; MOF, multiple organ failure.

therapy, especially when the CVP is low and associated with low flow. A CVP of more than $8 \mathrm{~mm} \mathrm{Hg}$ might also be considered an 'alarm' for potential venous congestion associated (or not) with fluid overload [15].

- GEDV and EVLW: These are volumetric parameters derived from transpulmonary thermodilution and are integrated into the $\mathrm{PiCCO}^{\mathrm{TM}}$ plus, $\mathrm{PiCCO}_{2}{ }^{\mathrm{TM}}$, and EV1000 ${ }^{\mathrm{ma}}$ monitors. EVLW can help in the identification of (cardiogenic or non-cardiogenic) pulmonary edema and has the potential to increase the safety of fluid therapy in patients with structural lung disease, acute respiratory distress syndrome, or congestive heart failure.

- The end-diastolic area of the left ventricle may be the most reliable static parameter of preload but is largely dependent on LV diastolic compliance. Its ability to accurately predict fluid responsiveness is limited.

\section{Functional hemodynamic parameters}

Positive pressure ventilation induces cyclical changes in intrathoracic pressure, which affect preload by decreasing venous return to the right heart and increasing venous return to the left ventricle. The degree of the resulting changes in LV SV (stroke volume variation; SVV) and pulse pressure (pulse pressure variation; PPV) better predict fluid responsiveness than do static parameters, when RV function is not a limitation and for a fixed tidal volume. Most devices using pulse contour analysis, including the current version of the noninvasive ClearSight monitor, display SVV and PPV. Despite the numerous validity criteria required to interpret such variations, these variables may help predict fluid responsiveness at different thresholds and have been integrated into hemodynamic optimization protocols [58].

Respiratory variations in the pulse oximeter plethysmographic waveform have been shown to predict fluid responsiveness in mechanically ventilated patients, similar to changes in the arterial pressure waveform [59]. The Masimo $^{\text {тм }}$ device (Masimo Corporation, Irvine, CA, USA) provides automated calculation of the pleth variability index (PVI) by measuring changes in perfusion index over a time interval including at least one complete respiratory cycle. The PVI has been shown to predict fluid responsiveness in various perioperative settings and has been integrated into fluid optimization algorithms. However, the PVI has the same limitations as the other dynamic parameters and has limited accuracy in the presence of vasoconstriction with or without the use of vasopressors [60-62].

\section{Limitations}

It is important to note that all of the dynamic variables have significant confounding factors [58]. The reliability of these indices is affected by spontaneous breathing activity, arrhythmias, right heart failure, decreased chest wall compliance, and increased intra-abdominal pressure, although most of these limitations are uncommon in the OR. Nevertheless, in the ICU, a relatively small proportion of patients present suitable criteria for these indices [63]. Another major limitation of dynamic parameters is that they are dependent on the size of the tidal volume. Some authors have suggested that they require a tidal volume of at least $8 \mathrm{~mL} / \mathrm{kg}$ body weight [64], although they have been successfully used with tidal volumes of 6 to $8 \mathrm{~mL} / \mathrm{kg}$ body weight $[61,62]$. A recent study and meta-analysis have indicated a decreased rate of post-operative complications when low tidal volumes are applied during anesthesia $[65,66]$, and increased use of protective ventilation (lower tidal volumes) in the OR may reduce the usefulness of dynamic parameters or at least require new interpretation rules. Finally, within a range of PPV values of $9 \%$ to $13 \%$, fluid responsiveness cannot always be reliably predicted; there is a 'gray zone' in which prediction of fluid responsiveness is difficult. One study [67] indicated that fluid responsiveness could not be reliably predicted by using dynamic measures in as many as $25 \%$ of anesthetized patients.

A PLR test has been suggested to overcome some of these limitations in dynamic evaluation but should be performed rigorously with simultaneous analysis of continuous $\mathrm{CO}$ monitoring. It is obviously impractical during most operative conditions [68]. In addition, the blood volume shift from the leg to the central compartment is non-predictable. In a hypovolemic state, it is reasonable to consider this volume shift less than that generated in 'normal' volemic conditions.

Despite these limitations and confounding factors, whenever possible, one is advised to assess fluid responsiveness by using the available functional hemodynamic parameters before attempting to increase $\mathrm{CO}$ with fluid 
administration. This approach can indicate if and when $\mathrm{CO}$ can be further increased by fluids and can identify when the flat portion of the cardiac function curve has been reached, thus preventing unnecessary fluid loading [58]. It is important to remember that, generally speaking, fluid responsiveness is not an (absolute) indication to give fluids. Decisions about fluid administration should be based not only on dynamic parameters but also on the likely risk associated with fluid administration. During surgery, systematic fluid administration in the presence of fluid responsiveness may improve postoperative outcomes [69].

\section{Mixed venous oxygen saturation}

Changes in $\mathrm{SvO}_{2}$ may reflect important pathophysiological changes in the relationship between $\mathrm{DO}_{2}$ and $\mathrm{VO}_{2}$, both of which may fluctuate significantly during the perioperative period.

Reorganization of the Fick equation shows that:

$$
\mathrm{SvO}_{2}=\mathrm{SaO}_{2}-\left(\mathrm{VO}_{2} /[\mathrm{CO} \times \mathrm{Hb} \times \mathrm{C}]\right),
$$

where $\mathrm{C}$ is the amount of oxygen bound to $1 \mathrm{~g}$ of hemoglobin $(\mathrm{Hb})$. From this equation, it is clear that $\mathrm{SvO}_{2}$ will decrease in the presence of hypoxemia, hypermetabolic states (increased $\mathrm{VO}_{2}$ ), a decrease in $\mathrm{CO}$, or anemia. Therefore, changes in $\mathrm{SvO}_{2}$ are directly proportional to those in $\mathrm{CO}$ but only when arterial oxygen saturation $\left(\mathrm{SaO}_{2}\right), \mathrm{VO}_{2}$, and $\mathrm{Hb}$ concentration remain constant. The $\mathrm{SvO}_{2}$ is around $75 \%$ in healthy patients but is closer to $70 \%$ in acutely ill patients who have a somewhat lower $\mathrm{Hb}$ concentration.

Central venous oxygen saturation $\left(\mathrm{ScvO}_{2}\right)$ is used as a surrogate for $\mathrm{SvO}_{2}$ when a PAC is not in situ, but has some limitations. Although the determinants of $\mathrm{ScvO}_{2}$ and $\mathrm{SvO}_{2}$ are similar, they cannot be used interchangeably [70-73]. Regional variations in the balance between $\mathrm{DO}_{2}$ and $\mathrm{VO}_{2}$ result in differences in the $\mathrm{Hb}$ saturation of blood in the superior and inferior vena cavae [74]. $\mathrm{ScvO}_{2}$ is affected disproportionately by changes in the upper body and does not reflect the $\mathrm{SvO}_{2}$ of coronary sinus blood [74]. In healthy individuals, $\mathrm{ScvO}_{2}$ may be slightly less than $\mathrm{SvO}_{2}$ [75] because of the high oxygen content of effluent venous blood from the kidneys [76], but this relationship is reversed during periods of hemodynamic instability as blood is redistributed to the upper body at the expense of the splanchnic and renal circulations [77]. In shock states, therefore, $\mathrm{ScvO}_{2}$ may exceed $\mathrm{SvO}_{2}$ by up to $20 \%$ [72]. This lack of equivalence has been demonstrated in various groups of acutely ill patients, including not only those with shock $[70,71,78]$ but also patients undergoing general anesthesia for cardiac $[73,79]$ and non-cardiac $[71,80]$ surgery. Even trends in $\mathrm{ScvO}_{2}$ do not closely reflect those of $\mathrm{SvO}_{2}[70,73,78]$.
Lower values of $\mathrm{ScvO}_{2}$ have been associated with more complications in patients undergoing cardiothoracic surgery [81]. Therefore, some authors have proposed to maintain $\mathrm{SvO}_{2}$ or $\mathrm{ScvO}_{2}$ above a cutoff value. In patients undergoing elective cardiac surgery, administration of intravenous fluid and inotropic therapy to attain a target $\mathrm{SvO}_{2}$ of at least $70 \%$ in the first 8 hours after surgery was associated with fewer complications and a shorter hospital stay [82]. In patients undergoing major abdominal (including aortic) surgery, achieving an oxygen extraction ratio of less than 27\% (from intermittent measurements of $\mathrm{ScvO}_{2}$ ) was associated with a shorter hospital stay [83].

During surgery, this measurement is less informative: firstly, hypoxemia is generally corrected; secondly, under anesthesia, especially with neuromuscular paralysis, oxygen use decreases in all tissues, so that reductions in $\mathrm{ScvO}_{2}$ are uncommon [84]. Nevertheless, low $\mathrm{ScvO}_{2}$ values imply first and foremost that $\mathrm{CO}$ may be inadequate. At the same time, very high $\mathrm{ScvO}_{2}$ values may imply that oxygen extraction is low, purporting a worse prognosis, at least during cardiac surgery [85].

\section{Blood lactate concentrations}

Lactate is a physiological substrate (carbohydrate) produced from pyruvate reduction during cytosolic glycolysis. In stable conditions, lactate production and elimination are equivalent (that is, 1,200 to $1,500 \mathrm{mmol}$ per day), leading to a stable blood lactate concentration of 0.8 to $1.2 \mathrm{mmol} / \mathrm{L}$. The net flux of lactate depends on the difference between release and uptake and varies among organs and with their energetic conditions [86]. Hyperlactatemia is associated with increased morbidity and mortality in critically ill patients [87-90]. Persistent hyperlactatemia is a more relevant indicator of poor outcome than an isolated elevated lactate value is. Hyperlactatemia is not always a consequence of tissue hypoxia; sometimes, it stems from an accelerated 'aerobic' glycolysis resulting from cytokine influence and catecholamine stimulation, a situation termed 'stress hyperlactatemia'. In practice, irrespective of the different metabolic modifications, an elevated lactate level indicates the presence of shock, and a decrease in lactate levels over time is a good indicator of effective treatment. Accordingly, repeated blood lactate measurements are recommended to monitor lactate production and clearance over time during surgery in high-risk patients.

\section{Management strategies based on perioperative monitoring}

There is good evidence that use of flow-based hemodynamic monitoring combined with hemodynamic manipulation in the perioperative period can reduce morbidity and sometimes mortality [83,91-97]. For a variety of reasons, however, this approach has not been adopted everywhere and has even been challenged [98]. Indeed, there 
Table 2 Options to optimize perioperative hemodynamic management in high-risk patients

\section{- Reactive}

Correct hypotension, tachycardia.

Give fluids in the presence of suspected hypovolemia with increased pulse pressure variation (PPV), systolic pressure variation, stroke volume variation (SW), or pleth variability index (PVI).

Identify a reduction in cardiac output and react promptly with fluid challenge.

Identify a reduction in central venous oxygen saturation $\left(\mathrm{ScvO}_{2}\right)$ and react promptly with fluid challenge.

\section{- Pro-active}

Maintain arterial pressure and heart rate within acceptable ranges.

Maximize stroke volume

Maintain PPV or SW at less than $12 \%$ or PVI at less than $14 \%$.

Maintain cardiac index $(\mathrm{Cl})$ or oxygen delivery $\left(\mathrm{DO}_{2}\right)$ in a desired range (for example, $\mathrm{Cl}$ of more than $4.5 \mathrm{~L} /$ minute $/ \mathrm{m}^{2}$ and $\mathrm{DO}_{2}$ of more than $600 \mathrm{~mL} /$ minute $/ \mathrm{m}^{2}$ ).

Maintain $\mathrm{ScvO}_{2}$ at more than $65 \%$.

have been some important problems with many clinical trials in the field, such as lack of blinding and suboptimal management of the control group.

There are basically two options to optimize perioperative cardiovascular management (Table 2), both of which aim to increase SV/CO by means of fluid loading (increase in cardiac preload) or inotrope administration (increase in contractility) or both:

- One option is reactive, by applying a rapid intervention only when a hemodynamic change occurs. One should then individualize treatment with fluid challenge techniques. The response to the rapid administration of a fluid bolus (for example, $250 \mathrm{~mL}$ ) can be evaluated during surgery (especially in the presence of signs of fluid responsiveness). The response can be monitored by evaluating the blood pressure or heart rate, but the $\mathrm{CO} / \mathrm{SV}$ response is much more accurate. Inotropic agents are added in the absence of an adequate response.

- The other option is pro-active and is based on a strategy of hemodynamic manipulation targeting supranormal $\mathrm{CO}$ or $\mathrm{DO}_{2}$ values to minimize the risk of tissue hypoperfusion. Adequate fluid administration is the first element of this strategy. Several studies have indicated that fluid management based on PPV, SVV, and SV optimization may decrease post-operative wound infections and possibly post-operative organ dysfunction [99,100]. Inotropic agents may be added if fluids alone are not sufficient for this purpose. There is a risk of overtreatment as excessive use of dobutamine has been associated with increased rates of complications [101]. The use of dopexamine as an alternative has given controversial results $[102,103]$.

\section{Conclusions}

Cardiovascular monitoring systems play an important role in optimizing perioperative hemodynamic management. Use of hemodynamic monitoring devices per se in the perioperative setting has not been linked to improved outcomes; however, appropriate measurement and interpretation of cardiovascular variables may help guide therapeutic interventions, which in turn can improve patient outcomes. The most appropriate system must be selected for the individual patient prior to surgery, taking into consideration the individual risks of the patient and the procedure. Appropriate interpretation of the information offered by hemodynamic monitoring requires the integration of several variables. Echocardiography is increasingly used as a first tool to identify a problem and help select initial treatment. To improve patient management and outcome, the clinician must understand the advantages and the limitations of the various tools and parameters used during perioperative care.

\section{Abbreviations}

CO: Cardiac output; CVC: Central venous catheter; CVP: Central venous pressure; $\mathrm{DO}_{2}$ : Oxygen delivery; EVLW: Extravascular lung water; GEDV: Global end-diastolic volume; Hb: Hemoglobin; ICG: Indocyanine green;

ICU: Intensive care unit; LV: Left ventricular; OR: Operating room; PAC: Pulmonary artery catheter; PACU: Post-anesthesia care unit; $\mathrm{PetCO}_{2}$ : Partial pressure of end-tidal carbon dioxide; PLR: Passive leg raising; PPV: Pulse pressure variation; PVI: Pleth variability index; RV: Right ventricular; $\mathrm{ScvO}_{2}$ : Central venous oxygen saturation; SV: Stroke volume; $\mathrm{SvO}_{2}$ : Mixed venous oxygen saturation; SW: Stroke volume variation; TEE: Transesophagel echocardiography; TTE: Transthoracic echocardiography; $\mathrm{VO}_{2}$ : Oxygen consumption; Zt: Vascular impedance.

\section{Competing interests}

$\mathrm{RP}$ has received equipment loans from LiDCO Ltd and has performed consultancy work for Edwards Lifesciences, Covidien (Dublin, Ireland), and Masimo. AP has received advisory board fees from Pulsion Medical Systems. $\mathrm{AH}$ has received lecture honoraria from Edwards Lifesciences and is an advisory board member without fees for UPmed (Munich, Germany). PF has received honoraria from Masimo for presentations in congresses. AR has received lecture and advisory board fees from LiDCO, Edwards Lifesciences, and Masimo. J-LV, PP, DP, SR, VMR, Cl, and GDR declare that they have no competing interests.

\section{Author details}

'Department of Intensive Care, Erasme Hospital, Université Libre de Bruxelles, 808 route de Lennik, 1070 Brussels, Belgium. ${ }^{2}$ AOU IRCCS San Martino-IST, Department of Surgical Sciences and Integrated Diagnostics, University of Genoa, Largo Rosanna Benzi 8, 16132 Genoa, Italy. ${ }^{3}$ Adult Critical Care Unit, Royal London Hospital, Whitechapel Road, London E1 1BB, UK. ${ }^{4}$ Department of Anesthesiology and Critical Care, Lariboisière Hospital, Assistance Publique-Hôpitaux de Paris, University of Paris 7 Denis Diderot, 75475 Paris, Cedex 10, France. ${ }^{5}$ Department of Anesthesiology and Intensive Care, Sheba Medical Center, Tel Aviv University, Tel Aviv 52621, Israel. ${ }^{6}$ Department of Anesthesiology and Intensive Care Medicine, University of Bonn, Sigmund-Freud-Str. 25, 53105 Bonn, Germany. ${ }^{7}$ Department of Human Health Sciences, Section of Anesthesiology and Intensive Care, University of Florence, Azienda Ospedaliero-Universitaria Careggi, Largo Giovanni Alessandro Brambilla 3, 50139 Florence, Italy. ${ }^{8}$ Department of Anesthesia and Intensive Care Medicine, University of Turin, S.Giovanni Battista Molinette Hospital, 10126 Turin, Italy. ${ }^{9}$ Medico-Surgical Intensive Care Unit, Saint-Roch 
University Hospital, University of Nice, 5 Rue Pierre Dévoluy, 06006 Nice, France. ${ }^{10}$ Service d'Anesthésiologie, Cliniques Universitaires Saint-Luc, Institute of Neuroscience (IoNS), Université catholique de Louvain, Avenue Hippocrate 10, 1200 Brussels, Belgium. ${ }^{11}$ Department of Anesthesia and Intensive Care Medicine, University Hospital, Medical School, University of Udine, P. le S. Maria della Misericordia 15, 33100 Udine, Italy. ${ }^{12}$ Department of Intensive Care Medicine, St George's Healthcare NHS Trust, Blackshaw Road, London SW17 0QT, UK.

\section{Published online: 08 May 2015}

\section{References}

1. Weiser TG, Regenbogen SE, Thompson KD, Haynes AB, Lipsitz SR, Berry WR et al. An estimation of the global volume of surgery: a modelling strategy based on available data. Lancet. 2008;372:139-44.

2. Jhanji S, Thomas B, Ely A, Watson D, Hinds CJ, Pearse RM. Mortality and utilisation of critical care resources amongst high-risk surgical patients in a large NHS trust. Anaesthesia. 2008;63:695-700.

3. Pearse RM, Harrison DA, James P, Watson D, Hinds C, Rhodes A, et al. Identification and characterisation of the high-risk surgical population in the UK. Crit Care. 2006;10:R81.

4. Lobo SM, de Oliveira NE. Clinical review: What are the best hemodynamic targets for noncardiac surgical patients? Crit Care. 2013;17:210

5. Khuri SF, Henderson WG, DePalma RG, Mosca C, Healey NA, Kumbhani DJ. Determinants of long-term survival after major surgery and the adverse effect of postoperative complications. Ann Surg. 2005;242:326-41.

6. Hamilton MA, Cecconi M, Rhodes A. A systematic review and meta-analysis on the use of preemptive hemodynamic intervention to improve postoperative outcomes in moderate and high-risk surgical patients. Anesth Analg. 2011;112:1392-402.

7. Gurgel ST. do Nascimento P Jr. Maintaining tissue perfusion in high-risk surgical patients: a systematic review of randomized clinical trials. Anesth Analg. 2011;112:1384-91

8. Cecconi M, Corredor C, Arulkumaran N, Abuella G, Ball J, Grounds RM, et al. Clinical review: Goal-directed therapy-what is the evidence in surgical patients? The effect on different risk groups. Crit Care. 2013;17:209.

9. Jhanji S, Lee C, Watson D, Hinds C, Pearse RM. Microvascular flow and tissue oxygenation after major abdominal surgery: association with post-operative complications. Intensive Care Med. 2009;35:671-7.

10. Marjanovic G, Villain C, Juettner E, zur Hausen A, Hoeppner J, Hopt UT, et al. Impact of different crystalloid volume regimes on intestinal anastomotic stability. Ann Surg. 2009;249:181-5.

11. Kulemann B, Timme S, Seifert G, Holzner PA, Glatz T, Sick O, et al. Intraoperative crystalloid overload leads to substantial inflammatory infiltration of intestinal anastomoses - a histomorphological analysis. Surgery. 2013;154:596-603.

12. Nessim C, Sideris L, Turcotte S, Vafiadis P, Lapostole AC, Simard S, et al. The effect of fluid overload in the presence of an epidural on the strength of colonic anastomoses. J Surg Res. 2013;183:567-73.

13. Pizov R, Eden A, Bystritski D, Kalina E, Tamir A, Gelman S. Hypotension during gradual blood loss: waveform variables response and absence of tachycardia. Br J Anaesth. 2012;109:911-8.

14. Vincent JL, Rhodes A, Perel A, Martin GS, Della Rocca G, Vallet B, et al. Clinical review: update on hemodynamic monitoring - a consensus of 16. Crit Care. 2011;15:229.

15. Legrand M, Dupuis C, Simon C, Gayat E, Mateo J, Lukaszewicz AC, et al. Association between systemic hemodynamics and septic acute kidney injury in critically ill patients: a retrospective observational study. Crit Care. 2013;17:R278.

16. Marik PE, Baram M, Vahid B. Does central venous pressure predict fluid responsiveness? A systematic review of the literature and the tale of seven mares. Chest. 2008;134:172-8

17. Vincent JL, Weil MH. Fluid challenge revisited. Crit Care Med. 2006;34:1333-7.

18. Thiele RH, Bartels K, Gan TJ. Cardiac output monitoring: a contemporary assessment and review. Crit Care Med. 2015;43:177-85.

19. Cannesson M, Pestel G, Ricks C, Hoeft A, Perel A. Hemodynamic monitoring and management in patients undergoing high risk surgery: a survey among North American and European anesthesiologists. Crit Care. 2011;15:R197.

20. Repesse $X$, Bodson L, Vieillard-Baron A. Doppler echocardiography in shocked patients. Curr Opin Crit Care. 2013;19:221-7.
21. Maltais S, Costello WT, Billings FT, Bick JS, Byrne JG, Ahmad RM, et al. Episodic monoplane transesophageal echocardiography impacts postoperative management of the cardiac surgery patient. J Cardiothorac Vasc Anesth. 2013;27:665-9.

22. Rhodes A, Cusack RJ, Newman PJ, Grounds RM, Bennett ED. A randomised controlled trial of the pulmonary artery catheter in critically ill patients. Intensive Care Med. 2002;28:256-64.

23. Harvey S, Harrison DA, Singer M, Ashcroft J, Jones CM, Elbourne D, et al. Assessment of the clinical effectiveness of pulmonary artery catheters in management of patients in intensive care (PAC-Man): a randomised controlled trial. Lancet. 2005;366:472-7.

24. Harvey S, Young D, Brampton W, Cooper AB, Doig G, Sibbald W, et al. Pulmonary artery catheters for adult patients in intensive care. Cochrane Database Syst Rev. 2006;3:CD003408.

25. Shah MR, Hasselblad V, Stevenson LW, Binanay C, O'Connor CM, Sopko G, et al. Impact of the pulmonary artery catheter in critically ill patients: metaanalysis of randomized clinical trials. JAMA. 2005;294:1664-70.

26. Vincent $J \mathrm{~L}$, Pinsky MR, Sprung $\mathrm{CL}$, Levy M, Marini JJ, Payen $\mathrm{D}$, et al. The pulmonary artery catheter: in medio virtus. Crit Care Med. 2008;36:3093-6.

27. Vincent JL. The pulmonary artery catheter. J Clin Monit Comput. 2012;26:341-5.

28. Gardner RM. Direct blood pressure measurement - dynamic response requirements. Anesthesiology. 1981;54:227-36.

29. Hamzaoui O, Monnet X, Richard C, Osman D, Chemla D, Teboul JL. Effects of changes in vascular tone on the agreement between pulse contour and transpulmonary thermodilution cardiac output measurements within an up to 6-hour calibration-free period. Crit Care Med. 2008;36:434-40.

30. Oren-Grinberg A. The PiCCO Monitor. Int Anesthesiol Clin. 2010;48:57-85.

31. Bendjelid K, Marx G, Kiefer N, Simon TP, Geisen M, Hoeft A, et al. Performance of a new pulse contour method for continuous cardiac output monitoring: validation in critically ill patients. Br J Anaesth. 2013;111:573-9.

32. Cecconi M, Fawcett J, Grounds RM, Rhodes A. A prospective study to evaluate the accuracy of pulse power analysis to monitor cardiac output in critically ill patients. BMC Anesthesiol. 2008;8:3.

33. Cecconi M, Dawson D, Grounds RM, Rhodes A. Lithium dilution cardiac output measurement in the critically ill patient: determination of precision of the technique. Intensive Care Med. 2009:35:498-504.

34. Senn A, Button D, Zollinger A, Hofer CK. Assessment of cardiac output changes using a modified FloTracNigileo algorithm in cardiac surgery patients. Crit Care. 2009;13:R32.

35. Cecconi M, Fasano N, Langiano N, Divella M, Costa MG, Rhodes A, et al. Goal-directed haemodynamic therapy during elective total hip arthroplasty under regional anaesthesia. Crit Care. 2011;15:R132.

36. Romano SM, Pistolesi M. Assessment of cardiac output from systemic arterial pressure in humans. Crit Care Med. 2002;30:1834-41.

37. Scolletta S, Bodson L, Donadello K, Taccone FS, Devigili A, Vincent JL, et al. Assessment of left ventricular function by pulse wave analysis in critically ill patients. Intensive Care Med. 2013;39:1025-33.

38. Romagnoli S, Romano SM, Bevilacqua S, Ciappi F, Lazzeri C, Peris A, et al. Cardiac output by arterial pulse contour: reliability under hemodynamic derangements. Interact Cardiovasc Thorac Surg. 2009;8:642-6.

39. Penaz J. Criteria for set point estimation in the volume clamp method of blood pressure measurement. Physiol Res. 1992;41:5-10.

40. Westerhof N, Lankhaar JW, Westerhof BE. The arterial Windkessel. Med Biol Eng Comput. 2009:47:131-41.

41. Stover JF, Stocker R, Lenherr R, Neff TA, Cottini SR, Zoller B, et al. Noninvasive cardiac output and blood pressure monitoring cannot replace an invasive monitoring system in critically ill patients. BMC Anesthesiol. 2009;9:6.

42. Bogert LW, Wesseling KH, Schraa O, Van Lieshout EJ, de Mol BA, van Goudoever J, et al. Pulse contour cardiac output derived from non-invasive arterial pressure in cardiovascular disease. Anaesthesia. 2010;65:1119-25.

43. Broch O, Renner J, Gruenewald M, Meybohm P, Schottler J, Caliebe A, et al. A comparison of the Nexfin $(R)$ and transcardiopulmonary thermodilution to estimate cardiac output during coronary artery surgery. Anaesthesia. 2012;67:377-83.

44. Bubenek-Turconi SI, Craciun M, Miclea I, Perel A. Noninvasive continuous cardiac output by the Nexfin before and after preload-modifying maneuvers: a comparison with intermittent thermodilution cardiac output. Anesth Analg. 2013;117:366-72.

45. Thom O, Taylor DM, Wolfe RE, Cade J, Myles P, Krum H, et al. Comparison of a supra-sternal cardiac output monitor (USCOM) with the pulmonary artery catheter. Br J Anaesth. 2009;103:800-4. 
46. Gueret G, Kiss G, Rossignol B, Bezon E, Wargnier JP, Miossec A, et al. Cardiac output measurements in off-pump coronary surgery: comparison between NICO and the Swan-Ganz catheter. Eur J Anaesthesiol. 2006;23:848-54.

47. Tachibana K, Imanaka H, Takeuchi M, Takauchi Y, Miyano H, Nishimura M. Noninvasive cardiac output measurement using partial carbon dioxide rebreathing is less accurate at settings of reduced minute ventilation and when spontaneous breathing is present. Anesthesiology. 2003;98:830-7.

48. Hofer CK, Buhlmann S, Klaghofer R, Genoni M, Zollinger A. Pulsed dye densitometry with two different sensor types for cardiac output measurement after cardiac surgery: a comparison with the thermodilution technique. Acta Anaesthesiol Scand. 2004;48:653-7.

49. Ball TR, Culp BC, Patel V, Gloyna DF, Ciceri DP, Culp Jr WC. Comparison of the endotracheal cardiac output monitor to thermodilution in cardiac surgery patients. J Cardiothorac Vasc Anesth. 2010;24:762-6.

50. Gujjar AR, Muralidhar K, Banakal S, Gupta R, Sathyaprabha TN, Jairaj PS. Noninvasive cardiac output by transthoracic electrical bioimpedence in postcardiac surgery patients: comparison with thermodilution method. J Clin Monit Comput. 2008;22:175-80

51. Squara P, Denjean D, Estagnasie P, Brusset A, Dib JC, Dubois C. Noninvasive cardiac output monitoring (NICOM): a clinical validation. Intensive Care Med. 2007:33:1191-4.

52. Raval NY, Squara P, Cleman M, Yalamanchili K, Winklmaier M, Burkhoff D. Multicenter evaluation of noninvasive cardiac output measurement by bioreactance technique. J Clin Monit Comput. 2008;22:113-9.

53. Garisto C, Favia I, Ricci Z, Romagnoli S, Haiberger R, Polito A, et al. Pressure recording analytical method and bioreactance for stroke volume index monitoring during pediatric cardiac surgery. Paediatr Anaesth 2015;25:143-9.

54. Critchley LA, Critchley JA. A meta-analysis of studies using bias and precision statistics to compare cardiac output measurement techniques. J Clin Monit Comput. 1999;15:85-91.

55. Cecconi M, Rhodes A, Poloniecki J, Della Rocca G, Grounds RM. Bench-tobedside review: the importance of the precision of the reference technique in method comparison studies - with specific reference to the measurement of cardiac output. Crit Care. 2009;13:201.

56. Squara $P$, Cecconi M, Rhodes $A$, Singer $M$, Chiche JD. Tracking changes in cardiac output: methodological considerations for the validation of monitoring devices. Intensive Care Med. 2009;35:1801-8.

57. Critchley LA, Lee A, Ho AM. A critical review of the ability of continuous cardiac output monitors to measure trends in cardiac output. Anesth Analg. 2010;111:1180-92.

58. Perel A, Habicher M, Sander M. Bench-to-bedside review: Functional hemodynamics during surgery - should it be used for all high-risk cases? Crit Care. 2013;17:203.

59. Desebbe O, Cannesson M. Using ventilation-induced plethysmographic variations to optimize patient fluid status. Curr Opin Anaesthesiol. 2008:21:772-8.

60. Sandroni C, Cavallaro F, Marano C, Falcone C, De Santis P, Antonelli M. Accuracy of plethysmographic indices as predictors of fluid responsiveness in mechanically ventilated adults: a systematic review and meta-analysis. Intensive Care Med. 2012;38:1429-37.

61. Forget $P$, Lois $F$, de Kock M. Goal-directed fluid management based on the pulse oximeter-derived pleth variability index reduces lactate levels and improves fluid management. Anesth Analg. 2010;111:910-4.

62. Forget $\mathrm{P}$, Lois F, Kartheuser A, Leonard D, Remue C, de Kock M. The concept of titration can be transposed to fluid management but does is change the volumes? Randomised trial on pleth variability index during fast-track colonic surgery. Curr Clin Pharmacol. 2013;8:110-4.

63. Mahjoub Y, Lejeune V, Muller L, Perbet S, Zieleskiewicz L, Bart F, et al. Evaluation of pulse pressure variation validity criteria in critically ill patients: a prospective observational multicentre point-prevalence study. $\mathrm{Br} J$ Anaesth. 2014;112:681-5.

64. Marik PE, Cavallazzi R, Vasu T, Hirani A. Dynamic changes in arterial waveform derived variables and fluid responsiveness in mechanically ventilated patients: a systematic review of the literature. Crit Care Med. 2009;37:2642-7.

65. Futier E, Constantin JM, Paugam-Burtz C, Pascal J, Eurin M, Neuschwander A, et al. A trial of intraoperative low-tidal-volume ventilation in abdominal surgery. N Engl J Med. 2013;369:428-37.

66. Serpa Neto A, Cardoso SO, Manetta JA, Pereira VG, Esposito DC, Pasqualucci Mde $\mathrm{O}$, et al. Association between use of lung-protective ventilation with lower tidal volumes and clinical outcomes among patients without acute respiratory distress syndrome: a meta-analysis. JAMA. 2012;308:1651-9.

67. Cannesson M, Le Manach Y, Hofer CK, Goarin JP, Lehot JJ, Vallet B, et al. Assessing the diagnostic accuracy of pulse pressure variations for the prediction of fluid responsiveness: a 'gray zone' approach. Anesthesiology. 2011;115:231-41

68. Monnet X, Teboul JL. Passive leg raising. Intensive Care Med. 2008;34:659-63.

69. Michard F. Long live dynamic parameters! Crit Care. 2014;18:413.

70. Chawla LS, Zia H, Gutierrez G, Katz NM, Seneff MG, Shah M. Lack of equivalence between central and mixed venous oxygen saturation. Chest. 2004; 126:1891-6.

71. Dueck MH, Klimek M, Appenrodt S, Weigand C, Boerner U. Trends but not individual values of central venous oxygen saturation agree with mixed venous oxygen saturation during varying hemodynamic conditions. Anesthesiology. 2005;103:249-57.

72. Reinhart K, Rudolph T, Bredle DL, Hannemann L, Cain SM. Comparison of central-venous to mixed-venous oxygen saturation during changes in oxygen supply/demand. Chest. 1989:95:1216-21.

73. Lorentzen AG, Lindskov C, Sloth E, Jakobsen CJ. Central venous oxygen saturation cannot replace mixed venous saturation in patients undergoing cardiac surgery. J Cardiothorac Vasc Anesth. 2008:22:853-7.

74. Glamann DB, Lange RA, Hillis LD. Incidence and significance of a 'step-down' in oxygen saturation from superior vena cava to pulmonary artery. Am J Cardiol. 1991;68:695-7.

75. Barratt-Boyes BG, Wood EH. The oxygen saturation of blood in the venae cavae, right-heart chambers, and pulmonary vessels of healthy subjects. J Lab Clin Med. 1957;50:93-106.

76. Dahn MS, Lange MP, Jacobs LA. Central mixed and splanchnic venous oxygen saturation monitoring. Intensive Care Med. 1988;14:373-8.

77. Lee J, Wright F, Barber R, Stanley L. Central venous oxygen saturation in shock: a study in man. Anesthesiology. 1972;36:472-8.

78. Ho KM, Harding R, Chamberlain J, Bulsara M. A comparison of central and mixed venous oxygen saturation in circulatory failure. J Cardiothorac Vasc Anesth. 2010;24:434-9.

79. Turnaoglu S, Tugrul M, Camci E, Cakar N, Akinci O, Ergin P. Clinical applicability of the substitution of mixed venous oxygen saturation with central venous oxygen saturation. J Cardiothorac Vasc Anesth. 2001;15:574-9.

80. Reinhart K, Kersting T, Fohring U, Schafer M. Can central-venous replace mixed-venous oxygen saturation measurements during anesthesia? Adv Exp Med Biol. 1986;200:67-72.

81. Collaborative Study Group on Perioperative ScvO2 Monitoring. Multicentre study on peri- and postoperative central venous oxygen saturation in highrisk surgical patients. Crit Care. 2006;10:R158.

82. Polonen P, Ruokonen E, Hippelainen M, Poyhonen M, Takala J. A prospective, randomized study of goal-oriented hemodynamic therapy in cardiac surgical patients. Anesth Analg. 2000;90:1052-9.

83. Donati A, Loggi S, Preiser JC, Orsetti G, Munch C, Gabbanelli V, et al. Goaldirected intraoperative therapy reduces morbidity and length of hospital stay in high-risk surgical patients. Chest. 2007;132:1817-24.

84. Van der Linden P, Schmartz D, Gilbart E, Engelman E, Vincent JL. Effects of propofol, etomidate, and pentobarbital on critical oxygen delivery. Crit Care Med. 2000;28:2492-9.

85. Perz S, Uhlig T, Kohl M, Bredle DL, Reinhart K, Bauer M, et al. Low and 'supranormal' central venous oxygen saturation and markers of tissue hypoxia in cardiac surgery patients: a prospective observational study. Intensive Care Med. 2011;37:52-9.

86. Fuller BM, Dellinger RP. Lactate as a hemodynamic marker in the critically ill. Curr Opin Crit Care. 2012;18:267-72.

87. Meregalli A, Oliveira RP, Friedman G. Occult hypoperfusion is associated with increased mortality in hemodynamically stable, high-risk, surgical patients. Crit Care. 2004;8:R60-5.

88. Bakker J, Coffernils M, Leon M, Gris P, Vincent JL. Blood lactate levels are superior to oxygen-derived variables in predicting outcome in human septic shock. Chest. 1991;99:956-62.

89. Jansen TC, van Bommel J, Schoonderbeek FJ, Sleeswijk Visser SJ, van der Klooster JM, Lima AP, et al. Early lactate-guided therapy in intensive care unit patients: a multicenter, open-label, randomized controlled trial. Am J Respir Crit Care Med. 2010;182:752-61

90. Jansen TC, van Bommel J, Woodward R, Mulder PG, Bakker J. Association between blood lactate levels, Sequential Organ Failure Assessment 
subscores, and 28-day mortality during early and late intensive care unit stay: a retrospective observational study. Crit Care Med. 2009;37:2369-74.

91. McKendry M, McGloin H, Saberi D, Caudwell L, Brady AR, Singer M. Randomised controlled trial assessing the impact of a nurse delivered, flow monitored protocol for optimisation of circulatory status after cardiac surgery. BMJ. 2004;329:258.

92. Pearse R, Dawson D, Fawcett J, Rhodes A, Grounds RM, Bennett ED. Early goal-directed therapy after major surgery reduces complications and duration of hospital stay. A randomised, controlled trial [ISRCTN38797445]. Crit Care. 2005;9:R687-93.

93. Bundgaard-Nielsen $\mathrm{M}$, Holte $\mathrm{K}$, Secher $\mathrm{NH}$, Kehlet $\mathrm{H}$. Monitoring of perioperative fluid administration by individualized goal-directed therapy. Acta Anaesthesiol Scand. 2007;51:331-40.

94. Wilson J, Woods I, Fawcett J, Whall R, Dibb W, Morris C, et al. Reducing the risk of major elective surgery: randomised controlled trial of preoperative optimisation of oxygen delivery. BMJ. 1999;318:1099-103.

95. Lobo SM, Salgado PF, Castillo VG, Borim AA, Polachini CA, Palchetti JC, et al. Effects of maximizing oxygen delivery on morbidity and mortality in highrisk surgical patients. Crit Care Med. 2000;28:3396-404.

96. Lopes MR, Oliveira MA, Pereira VO, Lemos IP, Auler Jr JO, Michard F. Goaldirected fluid management based on pulse pressure variation monitoring during high-risk surgery: a pilot randomized controlled trial. Crit Care. 2007;11:R100.

97. Pearse RM, Harrison DA, MacDonald N, Gillies MA, Blunt M, Ackland G, et al. Effect of a perioperative, cardiac output-guided hemodynamic therapy algorithm on outcomes following major gastrointestinal surgery: a randomized clinical trial and systematic review. JAMA. 2014;311:2181-90.

98. Morris C. Oesophageal Doppler monitoring, doubt and equipoise: evidence based medicine means change. Anaesthesia. 2013;68:684-8.

99. Scheeren TW, Wiesenack C, Gerlach H, Marx G. Goal-directed intraoperative fluid therapy guided by stroke volume and its variation in high-risk surgical patients: a prospective randomized multicentre study. J Clin Monit Comput. 2013;27:225-33.

100. Goepfert MS, Richter HP, Zu EC, Gruetzmacher J, Rafflenbeul E, Roeher K, et al. Individually optimized hemodynamic therapy reduces complications and length of stay in the intensive care unit: a prospective, randomized controlled trial. Anesthesiology. 2013;119:824-36.

101. Fellahi JL, Parienti JJ, Hanouz JL, Plaud B, Riou B, Ouattara A. Perioperative use of dobutamine in cardiac surgery and adverse cardiac outcome: propensity-adjusted analyses. Anesthesiology. 2008;108:979-87.

102. Pearse RM, Belsey JD, Cole JN, Bennett ED. Effect of dopexamine infusion on mortality following major surgery: individual patient data metaregression analysis of published clinical trials. Crit Care Med. 2008;36:1323-9.

103. Takala J, Meier-Hellmann A, Eddleston J, Hulstaert P, Sramek V. Effect of dopexamine on outcome after major abdominal surgery: a prospective, randomized, controlled multicenter study. European Multicenter Study Group on Dopexamine in Major Abdominal Surgery. Crit Care Med. 2000;28:3417-23. 